\title{
Reliability of Reinforced CONCRETE Girders UNDER CORRosion ATTACK
}

\author{
By Dan M. Frangopol, Fellow, ASCE, Kai-Yung Lin, ${ }^{2}$ and Allen C. Estes, ${ }^{3}$ Member, ASCE
}

\begin{abstract}
Corrosion of reinforcement is a major problem affecting a large number of reinforced concrete structures. At present, most reliability-based design studies of reinforced concrete structures do not consider the effects of corrosion. In this paper, we present a reliability-based approach to the design of reinforced concrete bridge girders that are under corrosion attack. Both reserve and residual reliability constraints are satisfied. The approach is based on the American Association of State Highway and Transportation Officials (AASHTO) standard specifications for highway bridges and on data of chloride corrosion of steel in concrete. First, the effects of corrosion on both moment and shear reliabilities are investigated. Second, a reliability-based design approach based on minimization of total material cost including corosion effects is proposed. This approach is demonstrated on several design examples. Finally, we suggest and illustrate a reliability-based design approach based on minimization of expected lifetime cost including corrosion effects and cost of failure consequences.
\end{abstract}

\section{INTRODUCTION}

Most of the design studies in reinforced concrete (RC) literature assume that the durability of $\mathrm{RC}$ structures can be taken for granted. However, many RC structures are exposed during their lifetime to environmental stressors (e.g., corrosion, expansive aggregate reactions) which attack the concrete and/or steel reinforcement (Kilareski 1980; Cady and Weyers 1994; West and Hime 1985; Takewaka and Matsumoto 1988; Mori and Ellingwood 1994a; Lin 1995; Thoft-Christensen 1995). A typical example is the nation's inventory of RC bridges. In recent years, significant distress and deterioration have been observed in many of these structures. Most of this is the result of reinforcing-steel corrosion due to chloride ion contamination of the concrete (Hyman and Hughes 1983). Deicing salt is a major source of chloride ions. In some instances, the degree of deterioration exceeds that predicted. Clearly, design should not focus solely on the reliability of the intact (undamaged) structure, but must also take into account the environmental stressors that reduce the integrity of RC structures.

In this paper, a design approach based on the early work of Frangopol and Hendawi (1994) and Lin and Frangopol (1996) is developed, in which a direct satisfaction of both reserve (intact) and residual (damaged) reliability constraints are satisfied. In this approach the design solution is associated with optimum cost in addition to satisfying both intact and damaged limit states.

The general cost-optimization problem is formulated as a nonlinear programming problem based on both the reserve reliability constraints associated with the American Association of State Highway and Transportation Officials (AASHTO) Standard Specifications for Highway Bridges (1992), and the residual reliability constraints resulting from considering environmental stressors due to corrosion. The problem is solved by a general reliability-based optimization software resulting from the marriage of a Monte Carlo simulation-based relia-

'Prof., Dept. of Civ., Envir,, and Arch. Engrg., Univ. of Colorado at Boulder, Boulder, CO 80309-0428.

${ }^{2}$ Proj. Mgr., Chung-Shen Inst. of Sci. and Technol., Taiwan, ROC; formerly, Grad. Student, Dept. of Civ., Envir., and Arch. Engrg., Univ. of Colorado at Boulder, Boulder, CO.

${ }^{3}$ Grad. Student, Dept. of Civ., Envir., and Arch. Engrg., Univ. of Colorado at Boulder, Boulder, $\mathrm{CO}$. bility evaluation program and a general purpose optimization software. Design examples of RC T-girders for highway bridges under corrosion illustrate the application of the proposed approach.

\section{CORROSION ATTACK}

Within the past 20 years, the deterioration of RC structures due to reinforcement corrosion has become an important problem. According to Kilareski (1980), the majority of the deterioration of the nation's RC bridges can be blamed on the corrosion of the reinforcing steel due to chloride ion contamination of the concrete. Kilareski (1980) describes this corrosion process as follows:

\footnotetext{
Under normal environmental conditions, steel reinforcing bars embedded in concrete do not corrode. Usually a thin film of iron oxide is present on the surface of the rebar when it is encased in the concrete. The high $\mathrm{pH}$ environment (approximately 13) associated with the hydration of the portland cement is usually sufficient to keep the protective film stable. However, sufficient concentrations of chloride ions can lower the $\mathrm{pH}$; and if moisture and oxygen are present, the rebar can begin to corrode. . The chloride ions are provided by the de-icing salts used on the highway system in the winter months. After a few winter seasons, there are usually enough chloride ions at the level of the rebar to break down the passive environment around the steel. Once the rebar begins to corrode and build up the red rust by-product of corrosion, it is only a matter of time before enough force is generated so that a spall or pot hole is formed...
}

In this study, corrosion is seen as a two-phase process. The first phase spans from the time of construction to the time of corrosion initiation, and the second phase follows until unacceptable levels of section loss have occurred. Chloride ions are the most common degradation agents. A high level of chloride concentration leads to a breakdown of the protective passivation layer surrounding the steel reinforcement.

According to West and Hime (1985), corrosion initiation occurs with chloride concentrations (at the level of the rebar) of about $0.83 \mathrm{~kg} / \mathrm{cu} \mathrm{m}(1.4 \mathrm{Ib} / \mathrm{cu} \mathrm{yd})$, for typical mixes of normal weight concrete of about $2,300 \mathrm{~kg} / \mathrm{cu} \mathrm{m}(145 \mathrm{lb} / \mathrm{cu} \mathrm{ft})$. The presence of large chloride concentrations at the surface of the concrete will cause the chloride concentrations at the rebar level to increase over time. The corrosion does not occur until the accumulation of chloride at the rebar surface exceeds the threshold value.

Studies indicate that chloride penetration (Cady and Weyers 


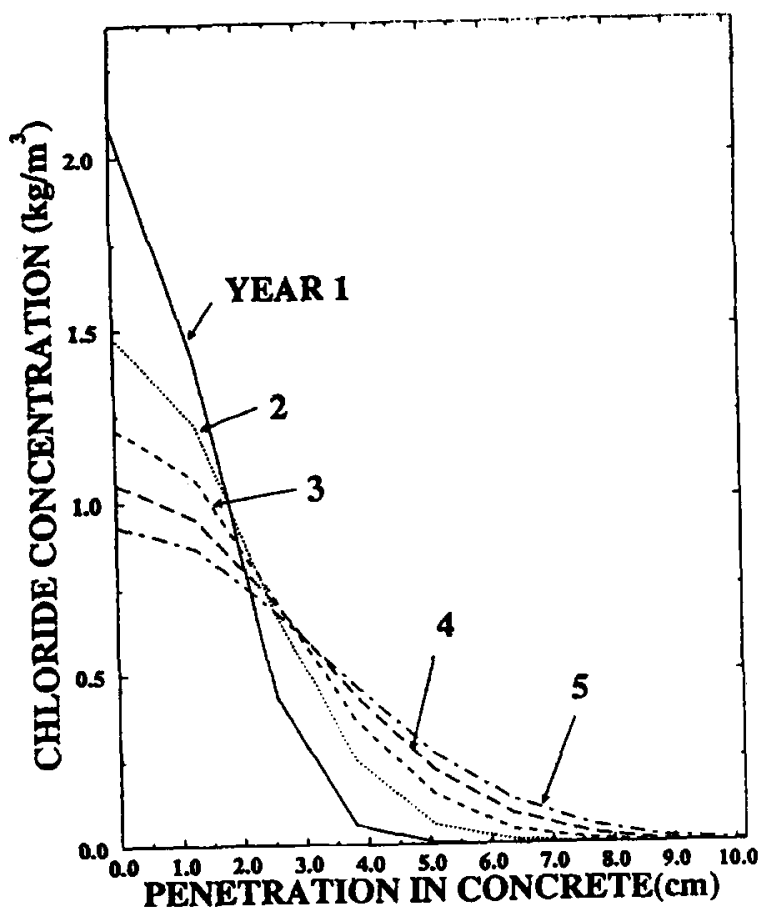

(a)

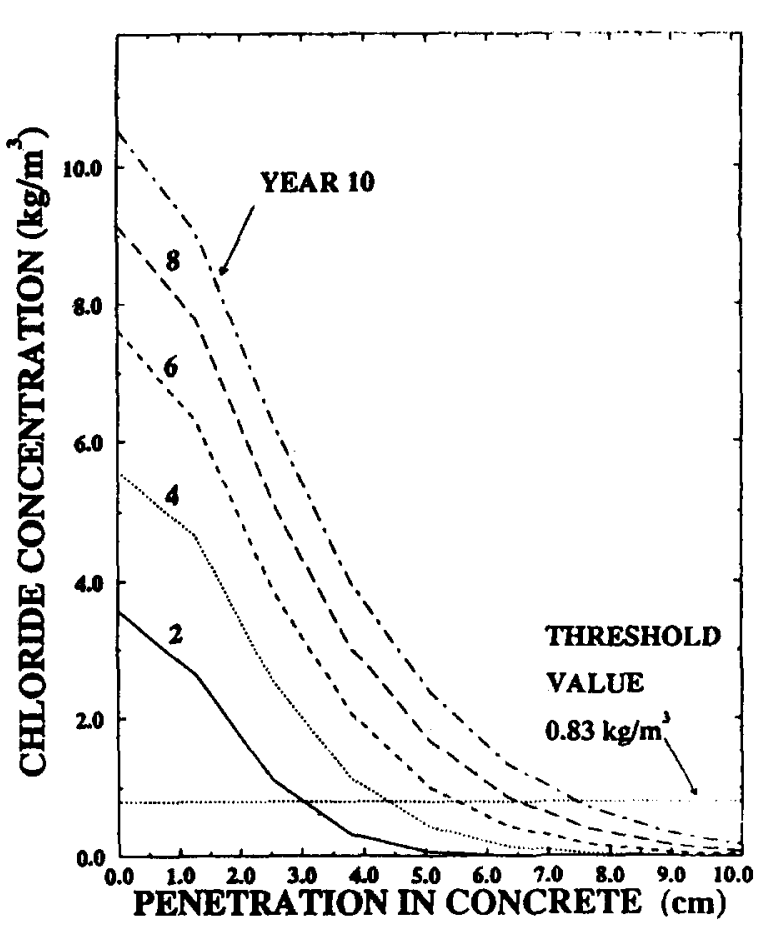

(b)

FIG. 1. Chloride Penetration In Concrete: (a) Single Year Application; (b) Ten Annual Equally Repeated Applications

1984; Takewaka and Matsumoto 1988) can be treated as a diffusion process and seems to follow Fick's law of diffusion

$$
\frac{\partial C_{x}}{\partial t}=\frac{D_{e} \partial^{2} C_{x}}{\partial x^{2}}
$$

where $C_{x}=$ chloride ion concentration at distance $x$ from the concrete surface after time $t$ of exposure to chloride sources; $D_{e}=$ effective chloride diffusion coefficient of concrete; and $t$ $=$ time. Depending on the boundary conditions and amount of chloride, several possible solutions to this differential equation are possible.

It was found (Takewaka and Matsumoto 1988) that the effective chloride diffusion coefficient of concrete $D_{e}$ (sq in./s) depends on the water-to-cement ratio, $w / c$, and the type of cement as follows:

$$
D_{e}=D_{w / c} D_{c}
$$

In (2) the coefficient denoting the effect of water-to-cement ratio, $D_{w / c}$ (sq in./s), is given as

$$
D_{w / c}=10^{-6.274-0.076 w / c+0.00113(w / c)^{2}}
$$

where $w / c$ is in percent and the coefficient denoting the effect of the cement $D_{c}$ is $1.2,1.0,0.3$, and 0.08 for high early strength portland cement, ordinary portland cement, blast furnace slag cement, and alumina cement, respectively.

During the winter season, the chloride ions are supplied by the deicing salts used on highway systems. After the winter season, there are usually enough chloride ions at the level of the rebar to induce corrosion. The total deicing salts commonly used in the winter season are considered applied once a year. For this case, the solution of (1) is

$$
C_{x, t}=\frac{G}{\sqrt{\pi D_{e} t}} \exp \left(\frac{-x^{2}}{4 D_{e} t}\right)
$$

where $C_{x, t}=$ chloride concentration at depth $x$ at time $t$; and $G=$ surface chloride content representing the amount of chloride deposited on the concrete surface (lb/cu yd).
Due to the heterogeneity of the near-surface concrete [which has a large number of cracks and voids and is estimated to extend to a depth of approximately two-thirds the diameter of the coarse aggregate (West and Hime 1985)], the near surface absorbs dissolved chlorides more quickly than solid concrete. For this reason, the validity of (4) in the near-surface concrete and/or after a very short time of application is questionable. In this study, (4) is used only to estimate the corrosion initiation period; the inaccuracies of this equation do not affect the results.

Eq. (4) is best suited for concrete structures exposed to a single application of chloride. Using the method of superposition, (4) is well suited for concrete structures that have been exposed to repeated applications of chloride deposits such as highway RC bridges. Fig. 1 shows the change in chloride concentration in both space (i.e., penetration in concrete) and time due to a single [Fig. 1(a)] and 10 annual equally repeated [Fig. 1(b)] applications of chloride deposits at the concrete surface. In Fig. 1, the values considered for $G$ and $D_{e}$ in (4) are 1.485 $\mathrm{kg} / \mathrm{cu} \mathrm{m}(2.5 \mathrm{lb} / \mathrm{cu} \mathrm{yd})$ and $3.26 \times 10^{-8} \mathrm{sq} \mathrm{cm} / \mathrm{s}\left(5.06 \times 10^{-9}\right.$ sq in./s), respectively. As shown in Fig. 1(a), after a single application (at time $t=0$ ) the chloride concentration decreases with time near the concrete surface [say, penetration below 1.8 $\mathrm{cm}(0.7$ in.)]. Clearly, this decrease is not found in Fig. 1(b) since the effect of chloride diffusion near the concrete surface is counteracted by that of annual equally repeated applications. By comparing the actual chloride concentration at the surface of reinforcement with the threshold concentration for initiation of corrosion [say, $0.83 \mathrm{~kg} / \mathrm{cu} \mathrm{m}(1.4 \mathrm{lb} / \mathrm{cu} \mathrm{yd})$ ], it is easy to find the corrosion initiation time required to depassivate the surface of the reinforcement. It should be mentioned that (4) may be modified to account for other factors that can influence the corrosion initiation time, such as repeated wetting and drying of the concrete at the surface. However, reliable data on the effects of these factors are not available.

Typical corrosion rates of steel in various environments have been reported in recent years. According to Ting (1989), the average corrosion rate $\nu$ for passive steel in concrete attacked by chlorides is about $100 \mu \mathrm{m} / \mathrm{yr}$ (0.004 in./yr). From 
Mori and Ellingwood's research (1994b), the typical corrosion rate, $v$, is a time-invariant random variable described by a lognormal distribution with mean, $\mu_{\nu}$, of $50 \mu \mathrm{m} / \mathrm{yr}(0.002 \mathrm{in} . / \mathrm{yr})$ and coefficient of variation, $V_{v}$, of $50 \%$. Because the corrosion rate changes with the environment, no accurate data is available to predict the real corrosion rate. Based on the average corrosion rates reported in Ting (1989) and Mori and Ellingwood (1994b), three corrosion rates of $64,89,114 \mu \mathrm{m} / \mathrm{yr}$

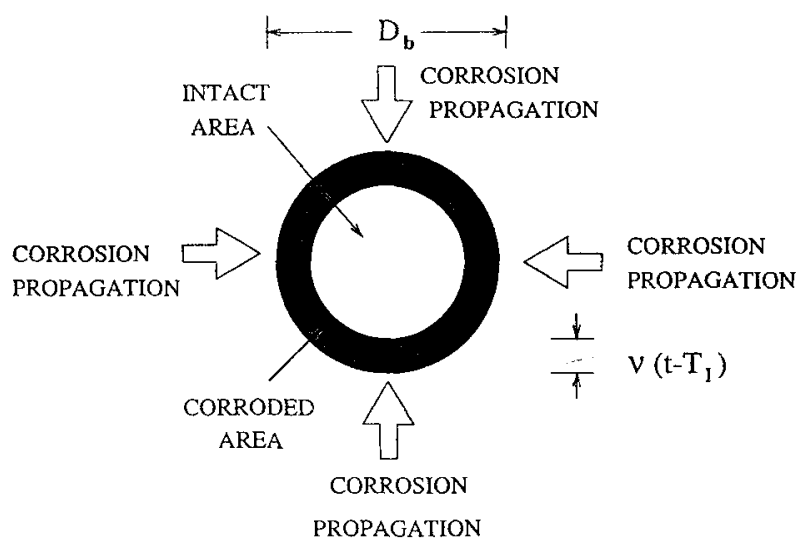

$(0.0025,0.0035,0.0045 \mathrm{in.} / \mathrm{yr})$ are used in this study to cover most cases. These rates may suggest a mean (i.e., $89 \mu \mathrm{m} / \mathrm{yr}$ ) and a standard deviation (i.e., $25 \mu \mathrm{m} / \mathrm{yr}$ ).

\section{CAPACITY LOSS}

The flexural strength of corroded reinforced concrete members depends mainly on the total available area of rebars in the tension zone. On the other hand, if only stirrups for shear reinforcement are used, the shear strength depends on the reinforcement placed perpendicular to the axis of the member.

For uniform corrosion (see Fig. 2), the total bending reinforcement area as a function of time $t$ is

$$
A_{s}(t)= \begin{cases}n \pi D_{b}^{2} / 4 & \text { for } t \leq T_{t} \\ n \pi\left[D_{b}-2 v\left(t-T_{I}\right)\right]^{2} / 4 & \text { for } t>T_{I}\end{cases}
$$

where $D_{b}=$ diameter of a rebar; $n=$ number of bars; $T_{l}=$ time of corrosion initiation; and $v=$ rate of corrosion. Factor 2 in (5) takes into account the uniform corrosion propagation process from all sides at the level of rebar (see Fig. 2). Under uniform corrosion, the cross-sectional area of a stirrup as a function of time is

$$
A_{v}(t)= \begin{cases}2 \pi D_{s}^{2} / 4 & \text { for } t \leq T_{l} \\ 2 \pi\left[D_{s}-2 v\left(t-T_{l}\right)\right]^{2} / 4 & \text { for } t>T_{I}\end{cases}
$$

(a)

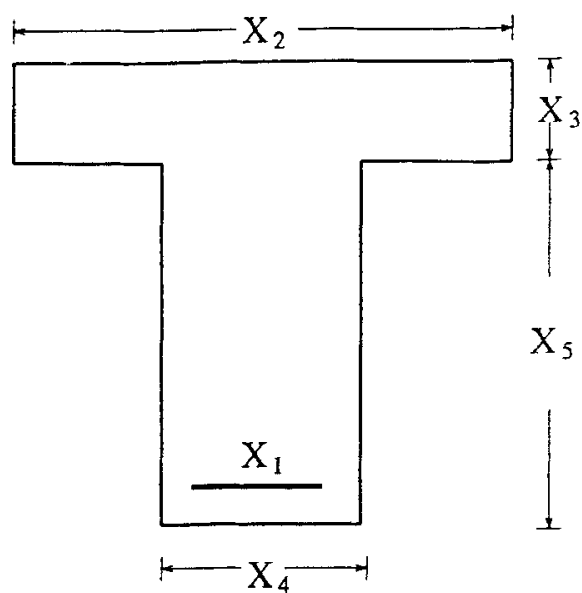

INTERVAL INTERVAL INTERVAL

$3 \quad 2 \quad 1$

(b)
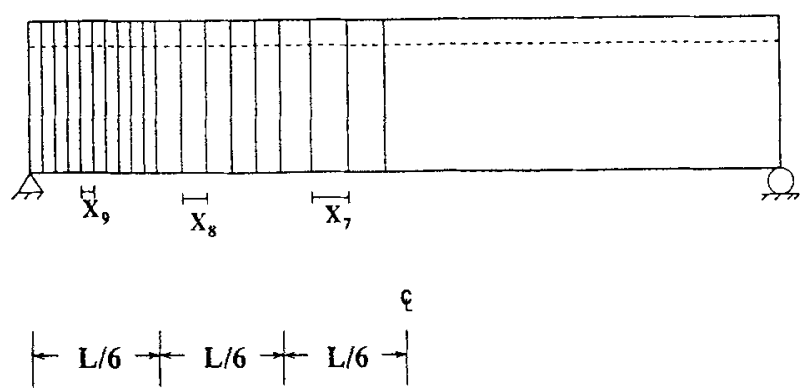

(c)

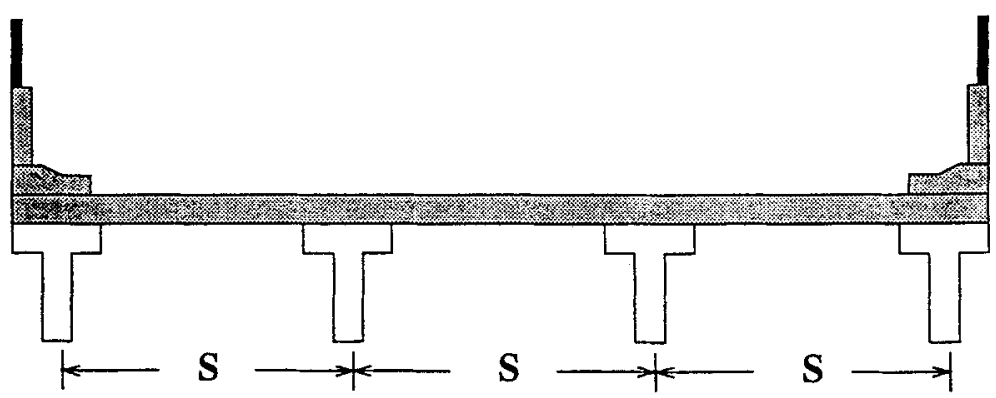

FIG. 3. Reinforced Concrete T-Girder: (a) Girder Cross Section; (b) Girder Elevation; (c) Bridge Cross Section 
where $D_{s}=$ diameter of a stirrup. Factor 2 takes into account the fact that the vertical branches of a stirrup are assumed to be corroded simultaneously.

As corrosion gradually progresses, the remaining capacities in both bending and shear decrease. The flexural strength of an isolated RC T-beam at time $t, M_{r}(t)$, may be computed as

$$
M_{r}(t)=A_{s}(t) f_{y}\left(d-\frac{a}{2}\right)
$$

where $f_{y}=$ yield strength of a reinforcing bar; $d=$ effective depth; and $a=$ depth of the equivalent rectangular stress block. On the other hand, the time-dependent shear strength is

$$
V(t)=V_{c}+V_{s}(t)
$$

In (8) it is assumed that the shear strength of concrete $V_{c}$ is time-independent. When only shear reinforcement perpendicular to the axis of the member is used, the shear strength due to stirrups is given as

$$
V_{s}(t)=\frac{A_{v}(t) f_{y} d}{s}
$$

where $A_{v}(t)$ is the area of the shear reinforcement within the

\begin{tabular}{|c|c|c|}
\hline $\begin{array}{c}\text { Notation } \\
(1)\end{array}$ & $\begin{array}{c}\text { Variable } \\
(2)\end{array}$ & $\begin{array}{c}\text { Units } \\
(3)\end{array}$ \\
\hline$X_{1}$ & Area of the tension steel reinforcement, $A_{t}$ & $6.45 \mathrm{sq} \mathrm{cm}(1 \mathrm{sq}$ in.) \\
\hline$X_{2}$ & Width of flange, $b$ & $2.54 \mathrm{~cm}$ (1 in.) \\
\hline$X_{3}$ & Thickness of flange, $h_{f}$ & $2.54 \mathrm{~cm}(1 \mathrm{in})$. \\
\hline$X_{4}$ & Width of web, $b_{w}$ & $2.54 \mathrm{~cm}$ (1 in.) \\
\hline$X_{3}$ & Height of web & $2.54 \mathrm{~cm}(1 \mathrm{in})$. \\
\hline$x_{6}$ & Area of the shear reinforcement & $6.45 \mathrm{sq} \mathrm{cm}(1 \mathrm{sq}$ in.) \\
\hline$X_{7}$ & Spacing of shear reinforcement in interval 1 & $2.54 \mathrm{~cm}(1 \mathrm{in})$. \\
\hline$X_{8}$ & Spacing of shear reinforcement in interval 2 & $2.54 \mathrm{~cm}(1 \mathrm{in})$. \\
\hline$X_{9}$ & Spacing of shear reinforcement in interval 3 & $2.54 \mathrm{~cm}(1 \mathrm{in})$. \\
\hline$X_{10}$ & Depth of equivalent rectangular stress block, $a$ & $2.54 \mathrm{~cm}(1 \mathrm{in})$. \\
\hline$X_{11}$ & Nominal flexural strength of $\mathrm{T}$ beam & $16.32 \mathrm{kN} / \mathrm{m}(1 \mathrm{kip} / \mathrm{in})$. \\
\hline$X_{12}$ & Reinforcement ratio, $\rho$ & - \\
\hline$X_{13}$ & Balanced reinforcement ratio, $\rho_{b}$ & 一 \\
\hline$X_{14}$ & Equivalent flange reinforcement & $6.45 \mathrm{sq} \mathrm{cm}(1 \mathrm{sq}$ in.) \\
\hline$X_{15}$ & Shear strength provided by concrete & $4.45 \mathrm{kN}$ (1 kip) \\
\hline$X_{16}$ & Shear strength provided by steel in interval 1 & $4.45 \mathrm{kN}$ (1 kip) \\
\hline$X_{17}$ & Shear strength provided by steel in interval 2 & $4.45 \mathrm{kN}$ (1 kip) \\
\hline$X_{18}$ & Shear strength provided by steel in interval 3 & $4.45 \mathrm{kN}$ (1 kip) \\
\hline$X_{19}$ & Total number of stirrups required & - \\
\hline$X_{20}$ & Maximum shear reinforcement spacing & $2.54 \mathrm{~cm}$ (1 in.) \\
\hline$X_{21}$ & Minimum bending reinforcement ratio & - \\
\hline$Y_{1}$ & Depth of slab & $2.54 \mathrm{~cm}(1 \mathrm{in})$. \\
\hline$Y_{2}$ & Center-to-center distance between girders & $30.5 \mathrm{~cm}(1 \mathrm{ft})$ \\
\hline$Y_{3}$ & Girder span length & $30.5 \mathrm{~cm}(1 \mathrm{ft})$ \\
\hline$Y_{4}$ & Specified yield strength of reinforcement, $f_{y}$ & $6.89 \mathrm{MPa}(1 \mathrm{ksi})$ \\
\hline$Y_{S}$ & Specified compressive strength of concrete $f_{c}^{\prime}$ & $6.89 \mathrm{MPa}(1 \mathrm{ksi})$ \\
\hline$Y_{6}$ & Dead load excluding girder weight & $14.59 \mathrm{kN} / \mathrm{m}$ (1 kip/ft) \\
\hline$Y_{r}$ & Maximum live load moment including impact & $1.36 \mathrm{kN} / \mathrm{m}(1 \mathrm{kjp} / \mathrm{ft})$ \\
\hline$Y_{\mathrm{B}}$ & $\begin{array}{l}\text { Maximum live load shear including impact in } \\
\text { interval } 1\end{array}$ & $4.45 \mathrm{kN}$ (1 kip) \\
\hline$Y_{9}$ & $\begin{array}{l}\text { Maximum live load shear including impact in } \\
\text { interval } 2\end{array}$ & $4.45 \mathrm{kN}$ (1 kip) \\
\hline$Y_{10}$ & $\begin{array}{l}\text { Maximum live load shear including impact in } \\
\text { interval } 3\end{array}$ & $4.45 \mathrm{kN}$ (1 kip) \\
\hline$Y_{11}$ & Unit weight of concrete & $\begin{array}{c}156.84 \mathrm{kN} / \mathrm{cu} \mathrm{m} \\
(1 \mathrm{kip} / \mathrm{cu} \mathrm{ft})\end{array}$ \\
\hline$Y_{12}$ & $\begin{array}{l}\text { Ratio of depth of equivalent rectangular com- } \\
\text { pression stress block to distance from fiber } \\
\text { of max. compressive strain to the neutral } \\
\text { axis, } a_{1}\end{array}$ & 一 \\
\hline
\end{tabular}
distance $s$ [see (6)], and $s=$ spacing between stirrups.

TABLE 1. Design Variables $(x)$ and Parameters $(Y)$
The thickness loss in a reinforcing bar is defined as

$$
D_{\text {loss }}=D_{\text {int }}-D_{\text {dam }}
$$

where $D_{i n s}=$ intact initial diameter of reinforcing bar; and $D_{\text {dam }}$ $=$ diameter of the damaged reinforcing bar after corrosion attack.

The loss of material due to corrosion causes a reduction in both bending and shear capacities of RC beams. Based on (7) and (8), and AASHTO (Standard 1992) requirements for the design of RC T-bridge girders, the moment and shear capacities can be calculated for both time-independent (intact) and time-dependent (damaged under corrosion) limit states.

Let us consider the RC T-girder shown in Fig. 3(a) and (b). The reliability-based structural optimum (RBSO) design of this girder requires the definition of the 21 design variables $\mathbf{X}$ and 12 parameters $\mathbf{Y}$ identified in Table 1 (Lin and Frangopol 1996). Table 2 shows time-independent (i.e., neglecting corrosion effects) optimum solutions for the RC T-girder whose independent design variables $X_{1}$ to $X_{5}$ and $X_{7}$ to $X_{9}$ are identified in Fig. 3(a) and (b). The bridge consists of four identical girders equally spaced as shown in Fig. 3(c).

The RBSO formulation takes into account all behavior and side constraints specified in the AASHTO (Standard 1992) specifications for highway bridges. The solution of this AASHTO-RBSO formulation is obtained by using nonlinear optimization software ADS (Vanderplaats 1986) and a Monte Carlo simulation software MCREL (Lin 1995). The objective of the optimization process is to minimize the total cost of steel and concrete $C_{T}$. This cost is sensitive to the ratio of the unit cost of steel to concrete $C_{S} / C_{C}$. The design solutions in Table 2 correspond to the following data (Lin 1995): depth of slab, $Y_{1}=17.78 \mathrm{~cm}$ ( $7 \mathrm{in}$.); center-to-center distance between girders, $S=Y_{2}=2.44 \mathrm{~m}(8 \mathrm{ft})$ [see Fig. 3(c)]; span length $L$ $=Y_{3}=18.30 \mathrm{~m}(60 \mathrm{ft}) ;$ mean yield strength of reinforcement, $\bar{Y}_{4}=\bar{f}_{y}=413.4 \mathrm{MPa}(60 \mathrm{ksi}) ;$ mean compressive strength of concrete, $\bar{Y}_{5}=\bar{f}_{c}^{\prime}=27.56 \mathrm{MPa}(4 \mathrm{ksi})$; ratio of the depth of the equivalent rectangular compression stress block to the distance between the fiber of maximum compressive strain and the neutral axis, $Y_{12}=a_{1}=0.85$; mean unit weight of concrete, $\bar{Y}_{11}=22.74 \mathrm{kN} / \mathrm{cu} \mathrm{m}(0.145 \mathrm{kip} / \mathrm{cu} \mathrm{ft})$; live loading, standard HS-20 trucks; distance from bottom fiber to centroid of bottom reinforcement, $\alpha=17.78 \mathrm{~cm}$ (7 in.); and concrete cover, $c=$ $7.62 \mathrm{~cm}$ ( $3 \mathrm{in}$.). The design meets the AASHTO (Standard 1992) specifications. The bridge consists of four identical equally spaced girders as shown in Fig. 3(c). The mean loading data for this bridge are as follows (Lin 1995): $\bar{Y}_{6}=13.57$ $\mathrm{kN} / \mathrm{m}(0.93 \mathrm{kips} / \mathrm{ft}) ; \bar{Y}_{7}=9,966 \mathrm{kN} / \mathrm{m}(683.1 \mathrm{kips} / \mathrm{ft}) ; \bar{Y}_{8}=$ $138.31 \mathrm{kN}(31.08 \mathrm{kips}) ; \bar{Y}_{9}=183.39 \mathrm{kN}(41.21 \mathrm{kips}) ;$ and $\bar{Y}_{10}$ $=228.51 \mathrm{kN}(51.35 \mathrm{kips})$. The coefficients of variation are 0.15 for $Y_{4}$ and $Y_{5}, 0.20$ for $Y_{6}, 0.243$ for $Y_{7}$ to $Y_{10}$, and 0.1 for $Y_{11}$. Finally, the value of the steel-to-concrete cost ratio, $C_{S} / C_{C}$, is assumed to be 50. As shown in Table 2, the optimum total cost $C_{T}$ increases with the allowable reliability level of limit states considered in the formulation $\beta_{M}^{*}=\beta_{S 1}^{*}=\beta_{S 2}^{*}=$ $\beta_{s 3}^{*}=\beta_{i}^{*}$, where $\beta_{M}^{*}$ is the allowable reliability level with respect to the bending moment, and $\beta_{s 1}^{*}, \beta_{s 2}^{*}$, and $\beta_{s 3}^{*}$ are allowable reliability levels with respect to shear in intervals 1,2 ,

\begin{tabular}{|c|c|c|c|c|c|c|c|c|c|c|c|}
\hline $\begin{array}{l}\text { Solution } \\
\text { (1) }\end{array}$ & $\begin{array}{l}\beta_{i}^{*} \\
(2)\end{array}$ & $\begin{array}{c}X_{1} \\
(\mathrm{sq} \mathrm{cm}) \\
(3)\end{array}$ & $\begin{array}{c}X_{2} \\
(\mathrm{~cm}) \\
(4)\end{array}$ & $\begin{array}{c}X_{3} \\
(\mathrm{~cm}) \\
(5)\end{array}$ & $\begin{array}{c}X_{4} \\
(\mathrm{~cm}) \\
(6)\end{array}$ & $\begin{array}{c}X_{5} \\
(\mathrm{~cm}) \\
(7)\end{array}$ & $\begin{array}{c}X_{6} \\
(\mathrm{sq} \mathrm{cm}) \\
(8)\end{array}$ & $\begin{array}{c}x_{7} \\
(\mathrm{~cm}) \\
(9)\end{array}$ & $\begin{array}{c}X_{\mathbf{s}} \\
(\mathrm{cm}) \\
(10)\end{array}$ & $\begin{array}{c}X_{8} \\
(\mathrm{~cm}) \\
(11)\end{array}$ & $\begin{array}{l}\text { Optimum total cost } \\
\text { (12) }\end{array}$ \\
\hline $\begin{array}{l}\text { A } \\
\text { B } \\
\text { C }\end{array}$ & $\begin{array}{l}3 \\
3.5 \\
4\end{array}$ & $\begin{array}{l}73.87 \\
86.52 \\
98.84\end{array}$ & $\begin{array}{l}69.95 \\
71.37 \\
77.83\end{array}$ & $\begin{array}{l}18.85 \\
21.69 \\
22.43\end{array}$ & $\begin{array}{l}32.49 \\
33.66 \\
35.51\end{array}$ & $\begin{array}{l}145.49 \\
149.78 \\
154.38\end{array}$ & $\begin{array}{l}0.606 \\
0.613 \\
0.594\end{array}$ & $\begin{array}{l}19.30 \\
21.84 \\
19.30\end{array}$ & $\begin{array}{l}18.80 \\
17.53 \\
18.80\end{array}$ & $\begin{array}{l}16.51 \\
15.24 \\
16.51\end{array}$ & $\begin{array}{l}578.6 \\
645.3 \\
716.1\end{array}$ \\
\hline
\end{tabular}
and 3 [see Fig. 3(b)], respectively.

The three theoretical (i.e., computer generated) solutions as-

TABLE 2. Reliability-Based Optimum Solutions Neglecting Corrosion Attack 

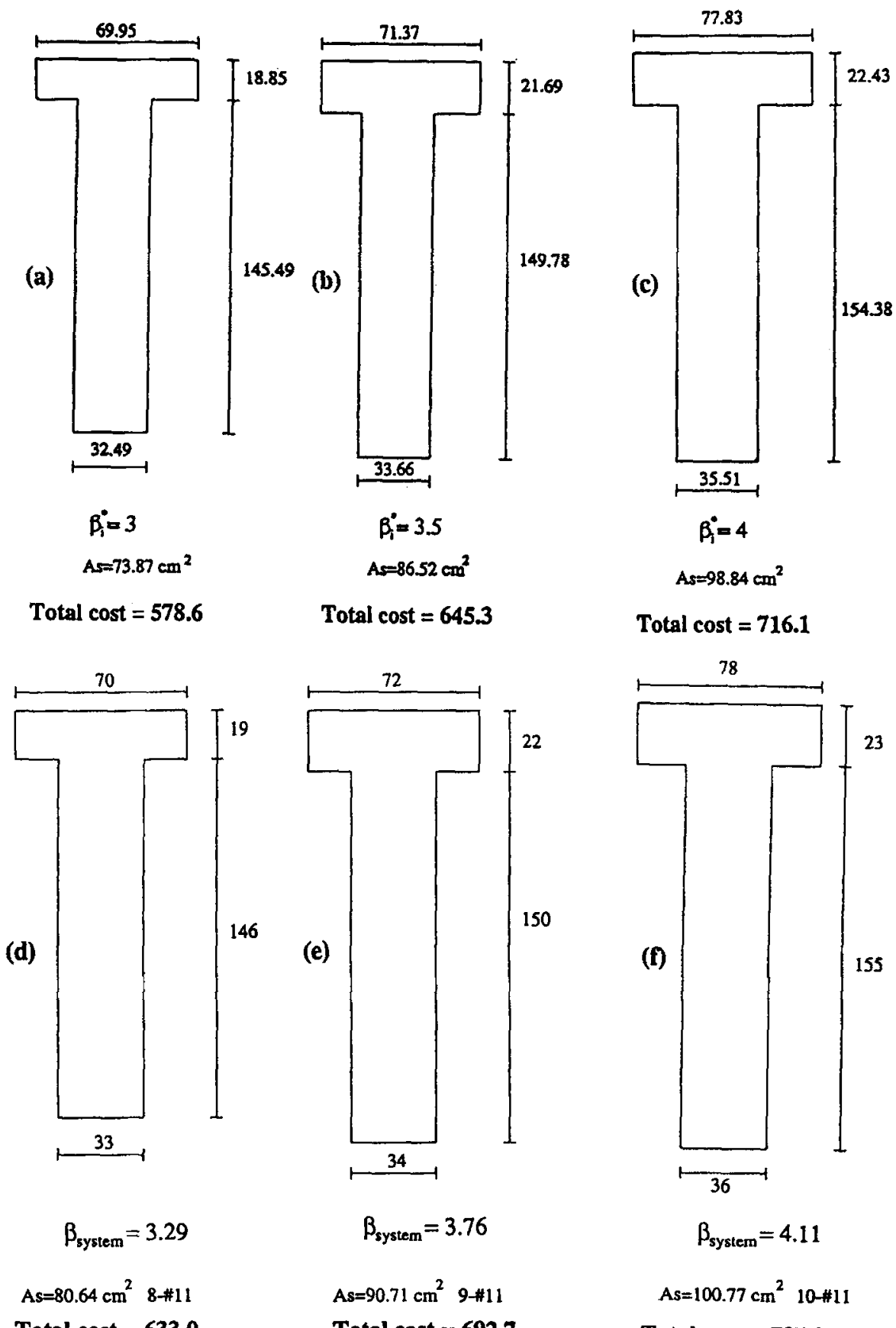

\section{Total cost $=716.1$}



$$
\begin{gathered}
\beta_{\text {system }}=3.29 \\
\text { As }=80.64 \mathrm{~cm}^{2} 8-\# 11
\end{gathered}
$$$$
\beta_{\text {system }}=3.76
$$$$
\text { As }=90.71 \mathrm{~cm}^{2} \text { 9-\#11 }
$$

Total cost $=633.0$

Total cost $=692.7$

FIG. 4. Optimum Solutions: (a) - (c) Computer Generated Solutions; (d) - (f) Actual Design Solutions

sociated with the results indicated in Table 2 are shown in Figs. 4(a)-(c) (Lin and Frangopol 1996). For a design that is actually going to be implemented, the area of steel resulting from the numerical optimization process would have to be changed to accommodate standard sizes of reinforcing steel. Also the optimized beam dimensions may have to be changed to meet standard dimension requirements. To illustrate this point, Figs. 4(d), 4(e), and 4(f) show the actual design solutions associated with the theoretical solutions presented in Figs. $4(a), 4(b)$, and $4(\mathrm{c})$, respectively. The notation $\beta_{\text {system }}$ denotes the reliability index of the beam with respect to all limit states considered.

In the presence of corrosion, the bending and shear strength of the RC T-girders in Table 2 will deteriorate. For this reason, a capacity loss analysis in bending and shear of girders A, B, and $C$ (see Table 2) has to be performed. In this analysis, the ratio of mean damaged capacity, $R_{\text {damage }}$, to the mean intact capacity, $\bar{R}_{\text {intact }}$, is defined as the residual capacity factor

$$
C_{R}=\bar{R}_{\text {damage }} / \bar{R}_{\text {inact }}
$$

The results of capacity loss analysis are indicated in Figs. 5(a), (b), and (c) for the optimum RC T-girders A, B, C (in Table 2), respectively. In these analyses, the thickness loss (10) represents the difference between the original (intact) diameter of the reinforcement and the damaged (corroded) diameter of the reinforcement. The results show the variation of the residual capacity factor $C_{R}$ with the thickness loss for bending moment $(M)$, and shear in the intervals $1\left(S_{1}\right), 2\left(S_{2}\right)$, and $3\left(S_{3}\right)$, Since, as defined in Fig. 3(b), $X_{7}, X_{8}$, and $X_{9}$ are the distances between stirrups in intervals 1,2 , and 3 , the shear strengths provided by steel reinforcement in these intervals at the time $t$ are 

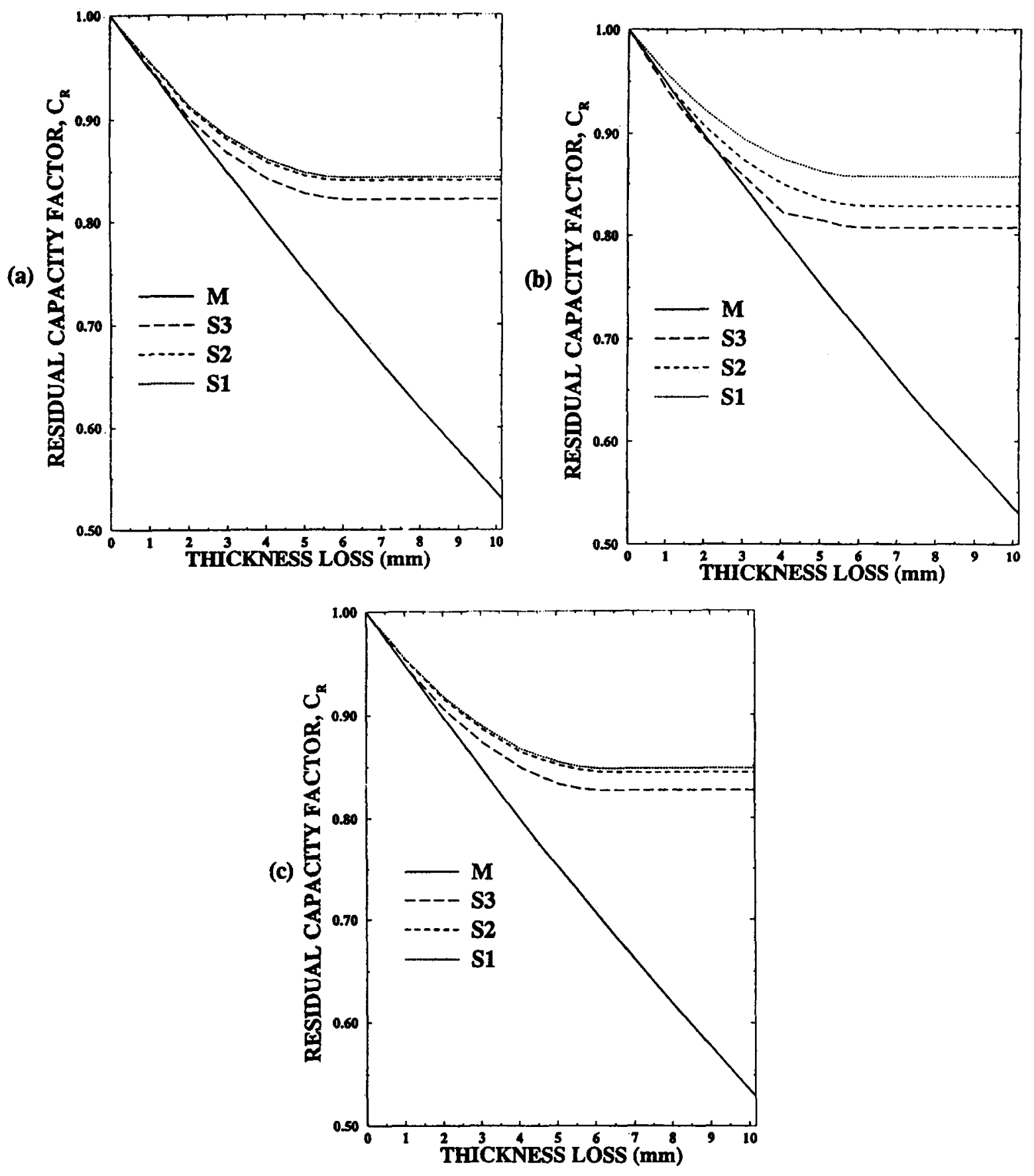

FIG. 5. Residual Capacity Factors for Moment and Shear versus Thickness Loss in Reinforcing Bars for RC T-Girders in Table 2: (a) Girder A; (b) Girder B; (c) Girder C

$V_{s, 1}(t)=A_{\nu}(t) f_{y} d / X_{7} ; \quad V_{s, 2}(t)=A_{v}(t) f_{y} d / X_{8} ; \quad V_{s, 3}(t)=A_{v}(t) f_{y} d / X_{9}$

As shown in Fig. 5, the bending capacity reduction due to corrosion is continuously increasing. Conversely, shear capacity reduction due to corrosion in steel reaches a point where the shear strength is contributed solely by concrete $\left[V_{c}\right.$ in (8)]. Although the moment capacities for the three beams are quite different, the ratio of the mean damaged to mean intact capacities appears identical for the moment; it is almost the same for shear.

\section{RELIABILITY LOSS}

The RC T-girders (Table 2) previously considered in the capacity loss analysis are examined herein for reliability loss due to corrosion. The results of the computations are illus- trated in Fig. 6. The reliability index, $\beta$, is plotted against the loss of reinforcement thickness due to corrosion, $D_{\text {loss }}$ [see (10)]. As expected from the results provided by the capacity loss analysis, the moment is the controlling limit state $\left(\beta_{M}<\right.$ $\beta_{s}$, where $\beta_{M}$ and $\beta_{s}$ are moment and shear reliability indices, respectively).

Consider now an environment where the amount of chloride deposited yearly on concrete surface is the same, $G=1.485$ $\mathrm{kg} / \mathrm{cu} \mathrm{m}(2.5 \mathrm{lb} / \mathrm{cu} \mathrm{yd})$. The concrete girder is made of ordinary portland cement with a water/cement ratio equal to $50 \%$. Then, according to (2) and (3), the coefficient of diffusion, $D_{s}$, is 3.7 $\times 10^{-7} \mathrm{sq} \mathrm{cm} / \mathrm{s}\left(5.6 \times 10^{-8} \mathrm{sq}\right.$ in./s).

The reinforcement cover is assumed to be $6.35 \mathrm{~cm}(2.5 \mathrm{in}$.). Considering annual equally repeated application of chloride deposits at the concrete surface, the chloride concentration levels at the surface of the rebar are $0.27,0.56$, and $0.84 \mathrm{~kg} / \mathrm{cu}$ $\mathrm{m}(0.45,0.94$, and $1.41 \mathrm{lb} / \mathrm{cu}$ yd) after 1,2 , and 3 years $\mathrm{fr} / \mathrm{m}$ 
(a)

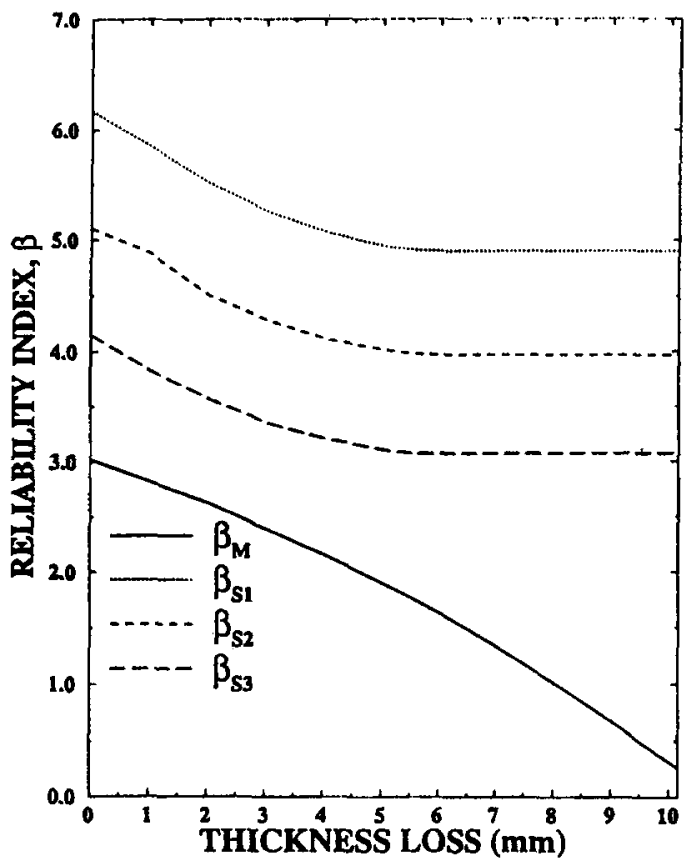

(b)

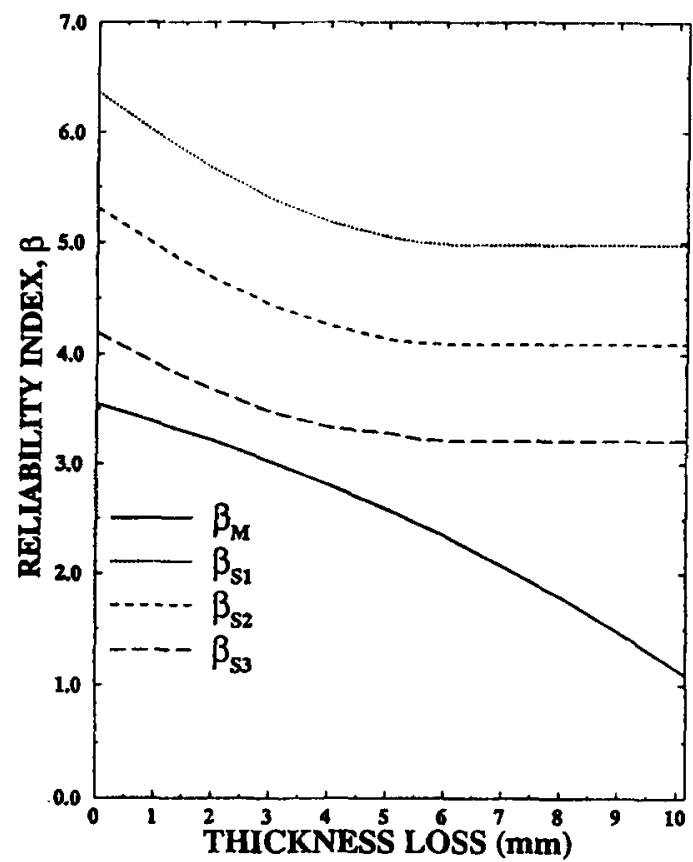

(c)

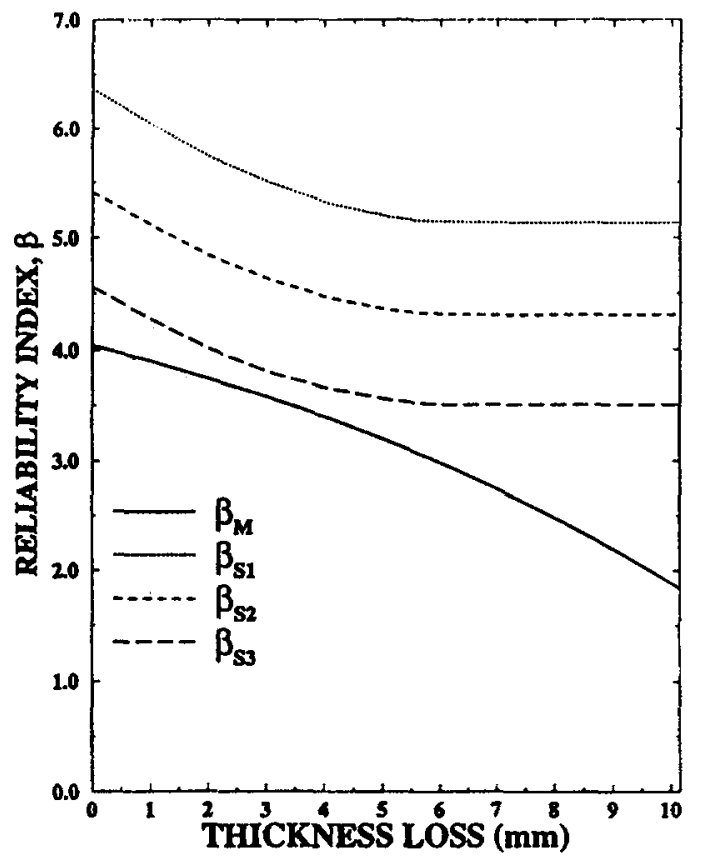

FIG. 6. Rellabllity Indices for Moment and Shear versus Thickness Loss in Reinforcing Bars for RC T-Girders in Table 2: (a) Girder A; (b) Girder B; (c) Girder C

the first application. Clearly, therefore, the steel corrosion initiates after three years of bridge service [i.e., the chloride concentration at a depth of $6.35 \mathrm{~cm}$ (2.5 in.) is greater than the threshold concentration of $0.83 \mathrm{~kg} / \mathrm{cu} \mathrm{m}(1.4 \mathrm{lb} / \mathrm{cu} \mathrm{yd})]$, which means $T_{I}=3 \mathrm{yr}$.

Admittedly, this study considers a worst case scenario of corrosion initiation. The chloride is placed on the deck, runs down the side of the beam at the same concentration, and starts the diffusion toward the tensile steel. While this is a conservative assumption, the lack of data on chloride concentration loss provides no reasonable alternative. The assumption may be justified when considering chloride penetration through the unprotected joints.

To understand the change in reliability with different corrosion rates $\nu$, the reliability index, $\beta$, is plotted for corrosion rates of $0.0064,0.0089$, and $0.0114 \mathrm{~cm} / \mathrm{yr}(0.0025,0.0035$, and $0.0045 \mathrm{in} . / \mathrm{yr}$ ), against the time of exposure in years of optimum RC T-beam design associated with $\beta_{i}^{*}=4$ (i.e., beam $\mathrm{C}$ in Table 2) [see Figs. 7(a), (b), and (c)]. Reliability indices are shown for maximum beam moment $\beta_{M}$, and maximum shear strength in intervals 1,2 , and 3 [see Fig. $3(\mathrm{~b})$ ], $\beta_{s 1}$, $\beta_{s_{2}}$, and $\beta_{s 3}$, respectively. Again, it is observed that the reliability index associated with moment is the controlling factor during the whole lifetime of the girder. It is interesting to note that, after corrosion initiation, the reliability associated with moment decreases monotonically with time, whereas shear reliability decreases during the first 25-30 years and then becomes constant. The constant value is associated with the shear reliability provided by concrete alone. For comparison purposes, the moment reliability for different corrosion rates is plotted in Fig. 8. As expected, a higher corrosion rate leads to a greater reduction in the reliability level. 


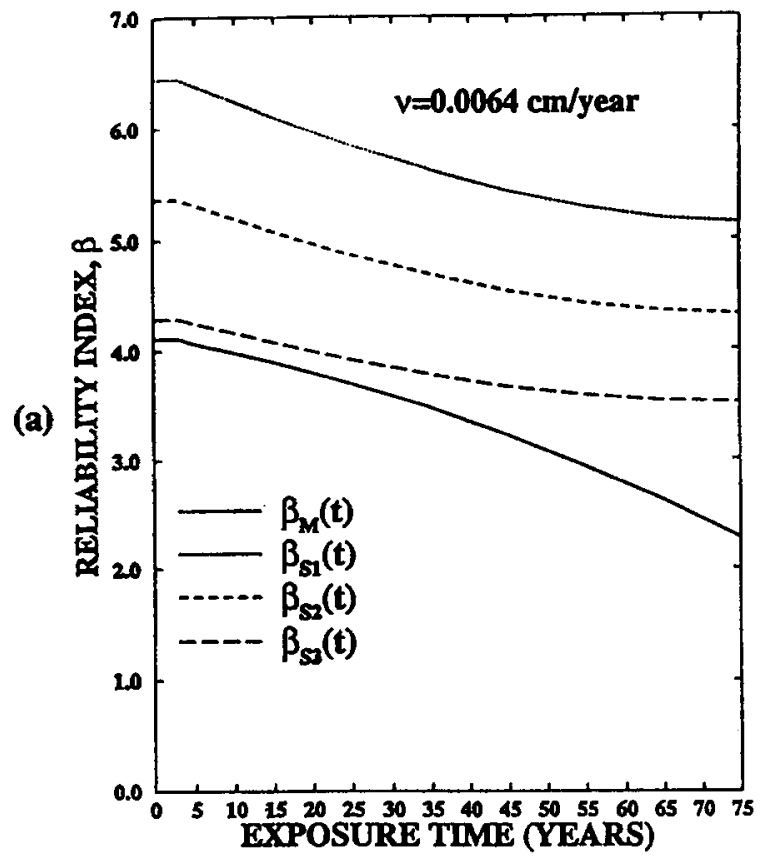

(b)

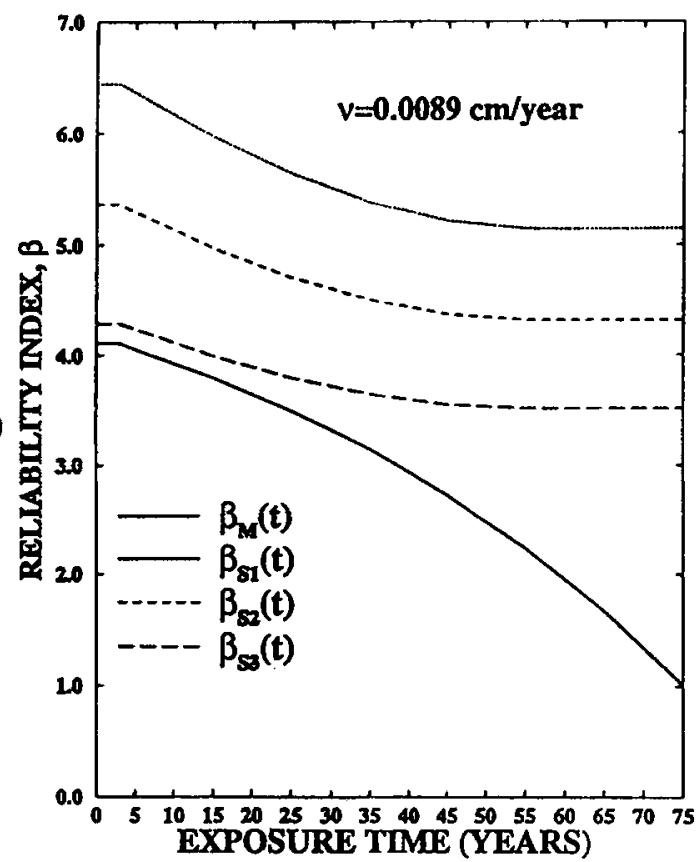

(c)

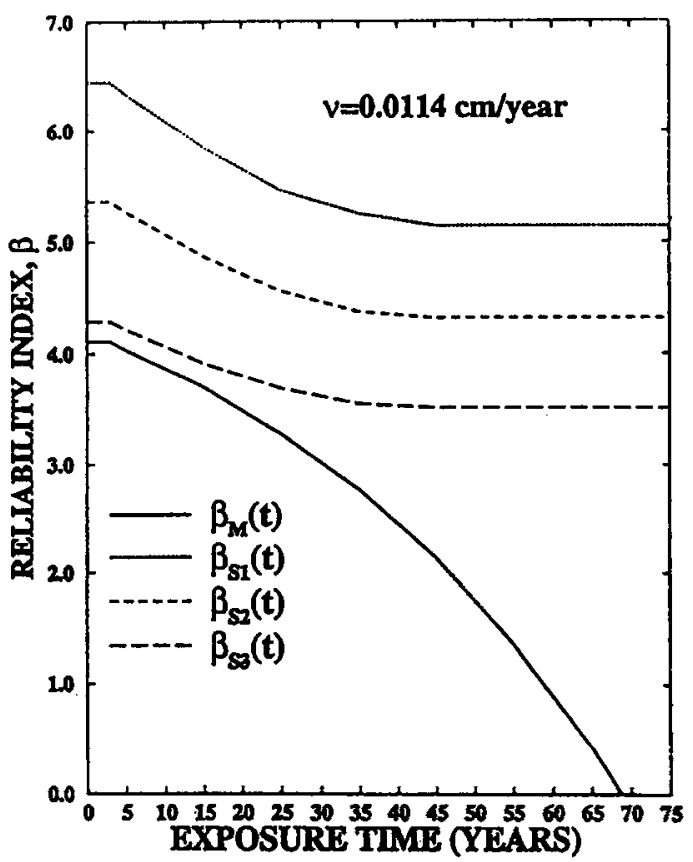

FIG. 7. Reliability Indices for Moment and Shear versus Time of Exposure to Corrosion of RC T-Girders in Table 2; Corrosion Rates: (a) $0.0064 \mathrm{~cm} / \mathrm{yr}$; (b) $0.0089 \mathrm{~cm} / \mathrm{yr}$; (c) $0.0114 \mathrm{~cm} / \mathrm{yr}$

\section{RELIABILITY-BASED DESIGN}

To include the corrosion effect in the optimum AASHTO time-independent reliability-based design formulation for RC T-bridge girders presented in Lin and Frangopol (1996), the corrosion rate associated with a given environment must be considered. Using time-variant reliability-based concepts, the minimum cost time-dependent RBSO formulation of the RC T-beam shown in Fig. 3(a) and (b) is mathematically expressed as follows:

Find the components of the design variable vector

$$
\mathbf{X}=\left(X_{\mathrm{t}}, X_{2}, \ldots, X_{9}\right)^{T}
$$

to minimize

$$
\begin{aligned}
C_{T} & =\frac{3}{4}\left(\frac{C_{S} Y_{3}}{144}\right) X_{1}+\left(\frac{C_{S} X_{19} X_{5}}{1,728}\right)\left(X_{3}+X_{5}-\alpha+0.5 X_{4}\right) \\
& +\left(\frac{C_{C} Y_{3}}{144}\right)\left(X_{2} X_{3}+X_{4} X_{5}\right)
\end{aligned}
$$

where $C_{T}=$ total cost; $C_{S}=$ unit cost of steel per $0.028 \mathrm{cu} \mathrm{m}$ $(1 \mathrm{cu} \mathrm{ft}) ; C_{C}=$ unit cost of concrete per $0.028 \mathrm{cu} \mathrm{m}(1 \mathrm{cu} \mathrm{ft})$; $\alpha=$ distance from the bottom fiber to the centroid of the reinforcement; and variables $X_{i}$ and $Y_{3}$ are defined in Table 1

Subject to the following constraints:

$$
\begin{gathered}
\beta_{1}(t)=\beta_{M}(t) \geq \beta_{1}^{*} ; \quad \beta_{2}(t)=\beta_{S 1}(t) \geq \beta_{2}^{*} \\
\beta_{3}(t)=\beta_{S 2}(t) \geq \beta_{3}^{*} ; \quad \beta_{4}(t)=\beta_{s 3}(t) \geq \beta_{4}^{*} \\
g_{3}=X_{12}-0.75 X_{13} \leq 0
\end{gathered}
$$




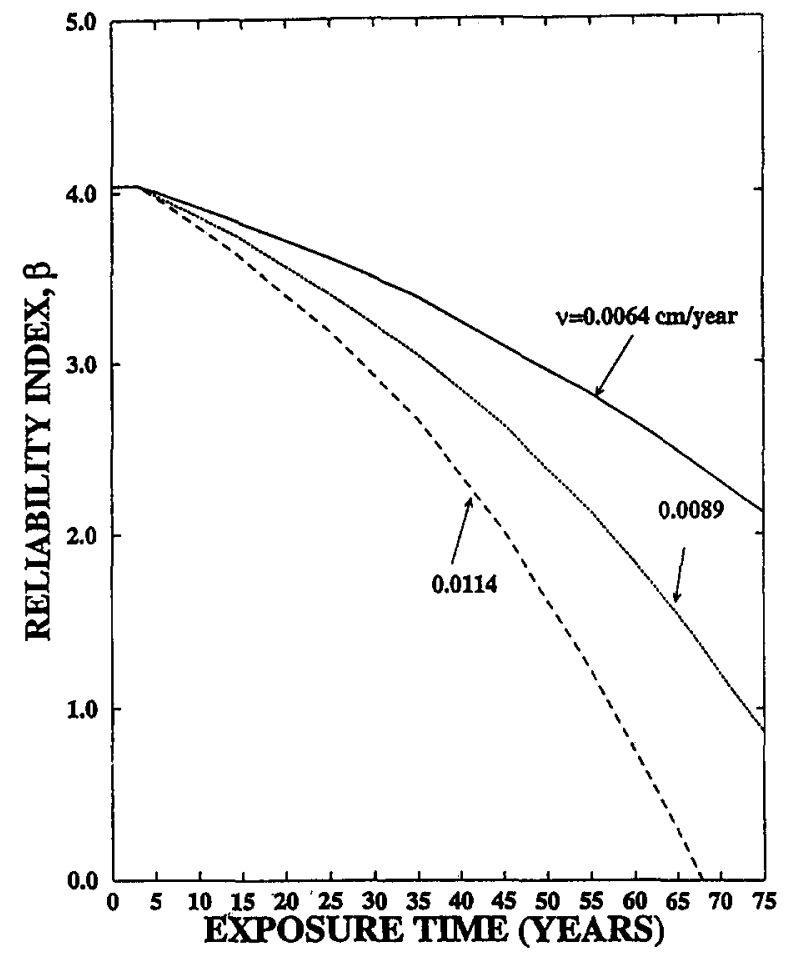

FIG. 8. Effects of Corrosion Rate and Time of Exposure to Corrosion on Moment Reliability of RC T-Girder C in Table 2

$$
\begin{array}{r}
g_{4}=X_{21}-X_{12} \leq 0 ; \quad g_{s a}=X_{7}-X_{20} \leq 0 \\
g_{s b}=X_{8}-X_{20} \leq 0 ; \quad g_{s c}=X_{9}-X_{20} \leq 0 \\
g_{6}=X_{18}-4 X_{15} \leq 0 ; \quad g_{7}=0.5 X_{4}-X_{3} \leq 0 \\
g_{8}=X_{2}-4 X_{4} \leq 0 ; \quad g_{9}=X_{4}-X_{2} \leq 0 \\
g_{10 i}=-X_{i} \leq 0, \quad(i=1,2, \ldots, 21)
\end{array}
$$

where $\beta_{i}^{*}=$ allowable reliability indices; $\beta_{M}=$ reliability index with respect to bending; and $\beta_{S 1}, \beta_{S 2}$, and $\beta_{S 3}=$ reliability indices with respect to shear in intervals 1, 2, and 3 [see Fig. 3(b)], respectively. The limit state functions associated with $\beta_{M}, \beta_{s 1}, \beta_{s 2}$, and $\beta_{s 3}$ are as follows:

$$
\begin{array}{r}
g_{M}(t)=\frac{X_{11}}{12}-Y_{7}-\frac{Y_{6} Y_{3}^{2}}{8}-\frac{\left(X_{2} X_{3}+X_{4} X_{5}\right) Y_{11} Y_{3}^{2}}{144 \times 8}=0 \\
g_{s 1}(t)=X_{15}+X_{16}-Y_{8}-\frac{Y_{6} Y_{3}}{6}-\frac{\left(X_{2} X_{3}+X_{4} X_{5}\right) Y_{11} Y_{3}}{144 \times 6}=0 \\
g_{s 2}(t)=X_{15}+X_{17}-Y_{9}-\frac{Y_{6} Y_{3}}{3}-\frac{\left(X_{2} X_{3}+X_{4} X_{5}\right) Y_{11} Y_{3}}{144 \times 3}=0 \\
g_{s 3}(t)=X_{15}+X_{18}-Y_{10}-\frac{Y_{6} Y_{3}}{2}-\frac{\left(X_{2} X_{3}+X_{4} X_{5}\right) Y_{11} Y_{3}}{144 \times 2}=0
\end{array}
$$

The behavior and size constraints specified in the AASHTO (Standard 1992) for the design of RC T-girders are considered in (21)-(34). It is important to notice that randomness in loads and resistances is explicitly considered in the above formulation. In fact, this formulation represents a time-variant extension of the optimum AASHTO reliability-based design formulation for intact RC girders presented in Lin and Frangopol (1996). For solving the RBSO formulation, the general purpose optimization software ADS (Vanderplaats 1986) was linked to the Monte Carlo simulation software MCREL (Lin 1995). MCREL is a Monte Carlo simulation-based general purpose reliability evaluation program developed at the University of Colorado and used to estimate both component and system reliability. Both the MCREL code and the ADSMCREL interface code are documented in Lin (1995).

\section{NUMERICAL EXAMPLE}

The RC T-beam example characterized by the reliabilitybased optimum solutions presented in Table 2 is considered again here, but in a time-dependent context due to the presence of corrosion. Therefore, several design variables (e.g., $X_{1}, X_{6}$, $\left.X_{12}\right)$ are now time-dependent. Using the previously presented time-dependent RBSO formulation, (15)-(34), Fig. 9 shows the results for three different corrosion rates. Allowable reliability level $\left(\beta_{i}^{*}=\beta^{*}\right)$ effects on the optimum total cost, $C_{T}(t)$, are shown in Fig. 9 for different corrosion rates, $\nu$, and exposure times, $t$. The optimum design solutions at time $t=0$ are the intact solutions (not affected by corrosion). As expected, the optimum total cost increases with time of exposure, corrosion rate, and target reliability level. As shown in Fig. 10 , the effect of corrosion rate on the optimum total cost required to maintain the same level of reliability $\left(\beta^{*}=3\right)$ increases with exposure time. Fig. 11 shows the effects of exposure time on the optimum design variables $X_{1}$ to $X_{5}$ [see Fig. 3(a)] for a given target reliability and corrosion rate. As expected, in order to maintain the same level of reliability over time in the presence of corrosion, the areas of tension steel reinforcement, $X_{1}$, and the web height, $X_{5}$, have to increase at a higher rate than the flange width, $X_{2}$, flange thickness, $X_{3}$, and web width, $X_{4}$. The optimum RC T cross sections required to maintain the level of reliability $\beta_{i}^{*}=\beta^{*}=3$ in an environment characterized by a corrosion rate of $\nu=0.0089 \mathrm{~cm} / \mathrm{yr}$ ( 0.0035 in./yr) are shown in Fig. 12 for four different exposure times. Clearly, for maintaining the same level of reliability, both steel and concrete areas have to increase with time of exposure to corrosion.

\section{OPTIMUM DESIGN BASED ON LIFETIME COST}

Minimum material cost $C_{T}$ may not be the most essential parameter characterizing the utility of a structure. If failure consequences are taken into account, a more general criterion for finding the optimal design derives from cost-benefit analysis. In this case, optimal design produces the minimum total expected cost (Frangopol and Moses 1994). The total expected cost considered here consists of two parts: the initial expected cost, $C_{T}(t)$, and the expected cost of failure during lifetime service, $C_{F, \text { tife }}$, which includes loss of the structure, loss of human life, and cost of injuries. A major obstacle in using this approach is the high uncertainty in the monetary value associated with fatalities and injuries resulting from structural failures. However, the sensitivity of the optimum lifetime cost to the expected cost of failure $C_{F, \text { life }}$, including fatalities and injuries, provides useful information to decision makers on the range of optimal lifetime reliability indices.

Structural optimization will be achieved within a framework of potential consequences of structural failure. Thus, it is necessary to introduce the lifetime failure probability $P_{f, \text { life }}$ in the objective function to be minimized as follows:

$$
\min C_{T, \text { life }}=C_{T}(t)+C_{F, \text { life }}=C_{T}(t)+C_{f} \times P_{f, l i f e}
$$

where $C_{T, l i j e}=$ total expected lifetime cost of the structure; $C_{T}(t)=$ initial expected cost of the structure; $C_{f}=$ cost associated with failure; and $t=$ exposure time to corrosion. Herein, the lifetime is considered 75 years and, therefore, the initial expected cost is $C_{T}(75)$. The probability of failure of the structure, $P_{f, \text { ife }}$ is approximated considering all limit states as a series system as

$$
P_{f, \text { iffe }}=1-\Phi\left[\beta_{\text {system }}(t)\right]
$$



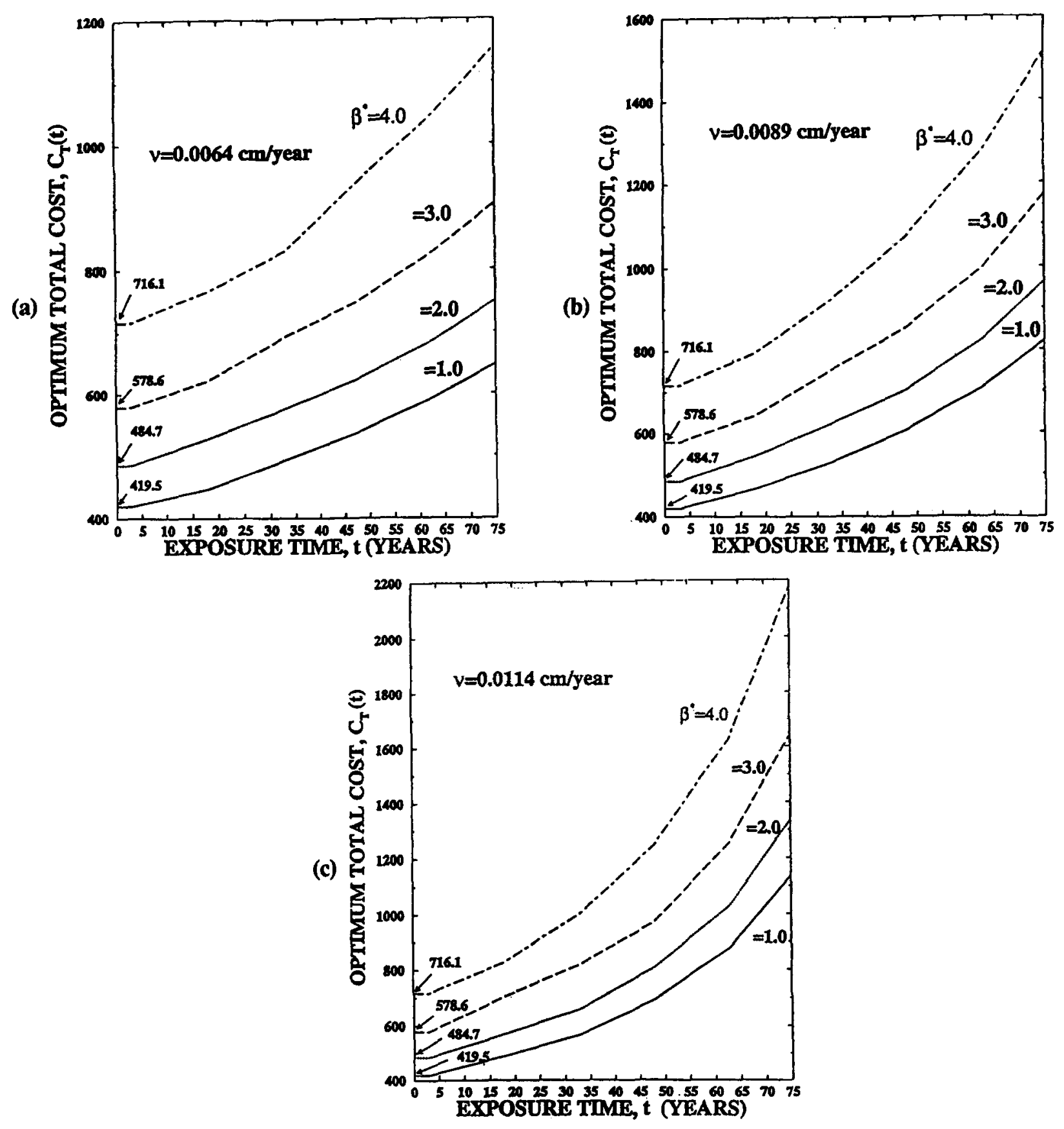

FIG. 9. Effects of TIme of Exposure to Corrosion and Allowable Reliability on the Optimum Total Cost of RC T-Girders under Different Corrosion Rates: (a) $0.0064 \mathrm{~cm} / \mathrm{yr}$; (b) $0.0089 \mathrm{~cm} / \mathrm{yr}$; (c) $0.0114 \mathrm{~cm} / \mathrm{yr}$

where $\Phi[$ ] = cumulative probability of a standard normal variable.

In general, the cost of failure, $C_{f}$, is largely determined by social factors. For different areas, cities, and countries, the cost of failure of the structure will be different. A number of approaches to evaluate $C_{f}$ have been proposed (see references cited in Frangopol and Moses 1994). The reader is referred to Lin (1995) for a detailed description of lifetime costs including also maintenance, inspection, and repair costs.

Fig. 13 shows the total expected lifetime (i.e., 75 years) cost, $C_{T, \text { ije }}$, as a function of the lifetime reliability index, $\beta_{\text {iffe }}$, for a corrosion rate of $\nu$ of $0.0064 \mathrm{~cm} / \mathrm{yr}(0.0025 \mathrm{in} . / \mathrm{yr})$. In order to study the sensitivity of the optimum lifetime cost to the expected cost associated with failure, Figs. 13(a) and 13(b) are associated with a failure cost $C_{f}$ of $10,000 C_{c}$ and $30,000 C_{C}$, respectively, where $C_{C}=$ unit cost of concrete.
These figures refer to the RC T-beams whose optimal initial (material) costs are shown in Fig. 9(a) for different exposure times and allowable reliability levels. In fact, the total material costs $C_{T}(75)$ in Figs. 13(a) and 13(b) at lifetime reliability levels 1.0, 2.0, 3.0, and 4.0 are given in Fig. 9(a) at 75 years of exposure to corrosion. The total initial (material) $\operatorname{cost} C_{T}(75)$ increases and the expected cost of failure $C_{F . l i j e}$ decreases with the increase in the lifetime reliability index. Consequently, there is a balance point at which the total expected lifetime cost $C_{\text {T.use }}$ is minimized. As shown in Fig. 13, the optimum lifetime design depends on the failure costs. Figs. 13(a) and 13(b) show optimal lifetime reliability indices of about 2.5 and 3.0 for failure costs of $10,000 C_{C}$ and $30,000 C_{C}$, respectively. Consequently, as the failure consequences are higher (i.e., failure cost increases), there is a need to design for a higher lifetime reliability level. 


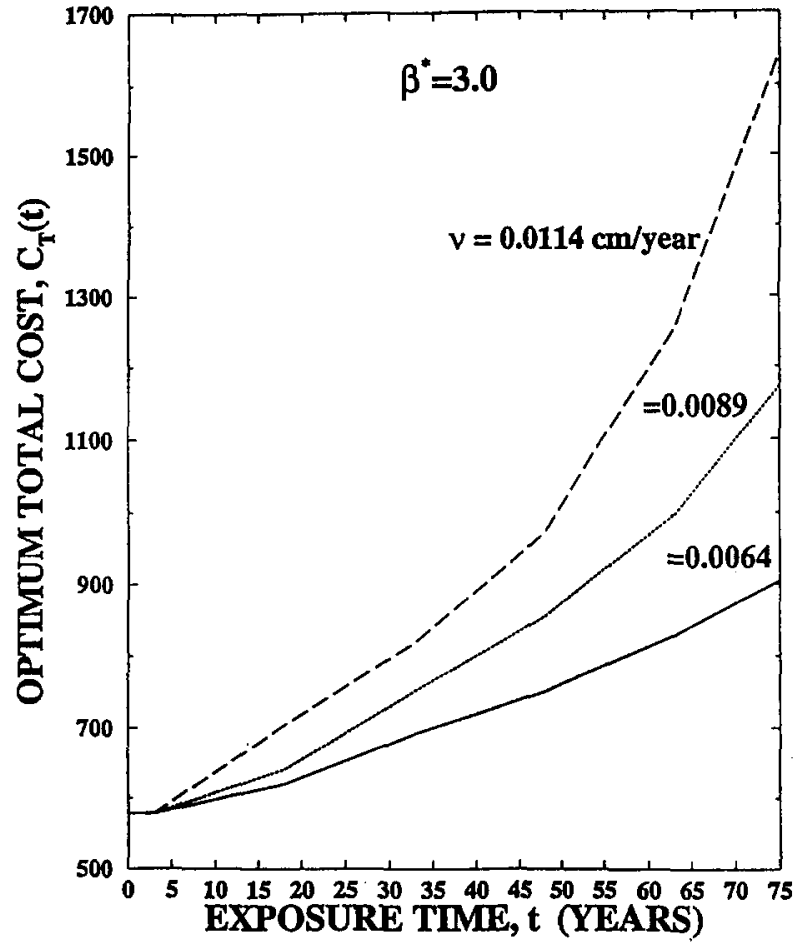

FIG. 10. Effects of Corrosion Rate and Time of Exposure to Corrosion on the Optimum Total Cost of RC T-Girder A in Table 2

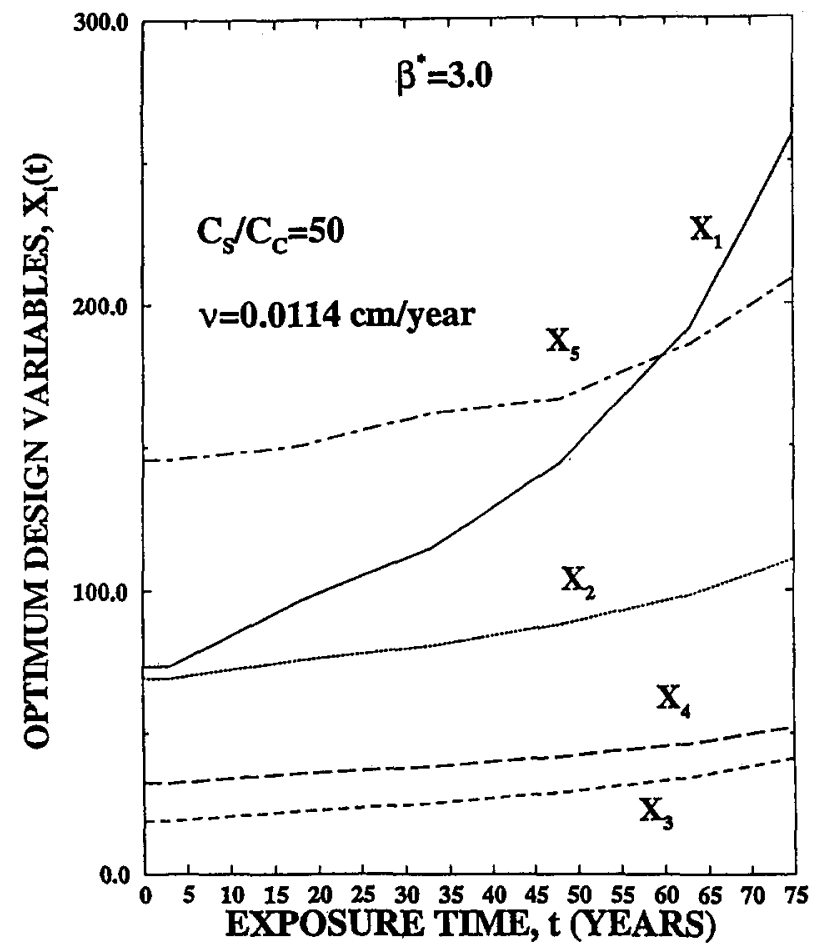

FIG. 11. Optimum Design Variables $X_{1}$ to $X_{5}$ versus Time of Exposure to Corrosion for a Given Reliabllity Level and Corrosion Rate

\section{CONCLUSIONS}

A reliability-based design approach of RC bridge girders under corrosion has been proposed. The formulation is broad and includes both intact (undamaged) constraints (under normal environmental conditions) specified in the AASHTO (Standard 1992) specifications for highway bridges and residual (damaged) constraints due to chloride corrosion of steel in concrete.

Unlike conventional RC design, which is based on satisfy-
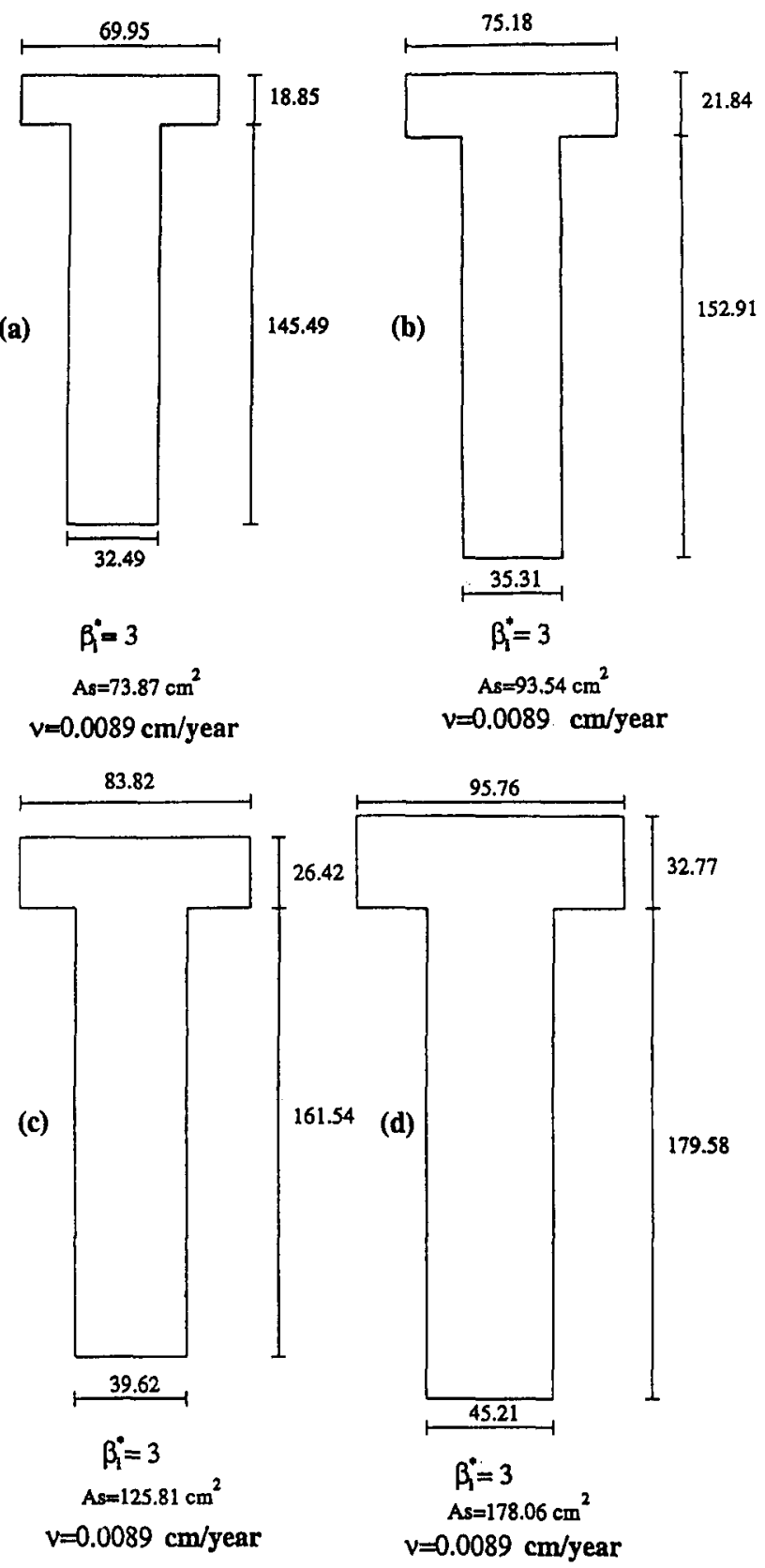

FIG. 12. Optimum RC T-Girder Cross Sections for Different Exposure Times: (a) 0 Years; (b) 25 Years; (c) 50 Years; (d) 75 Years (All Dimensions Are Shown in cm)

ing code constraints only, the proposed reliability-based approach uses the material cost or the expected lifetime cost as the objective to be minimized. Consequently, the proposed approach, based on both time-dependent reliability and optimization, is more rational than the conventional design approach in searching for the best solution.

The reliability of RC members exposed to chloride ion contamination of concrete deteriorates over time. The loss in reliability can be blamed on the corrosion of the reinforcing steel. The proposed approach has accounted for this effect. From the numerical examples, it was found that under the same corrosion rate, the loss in moment reliability is generally larger than the loss in shear reliability.

Maintaining the reliability of RC girders under corrosion during their service life at or above an established target reliability level can be achieved by using the proposed design approach. The numerical examples showed that corrosion rates, exposure times, and target reliability levels affect both 

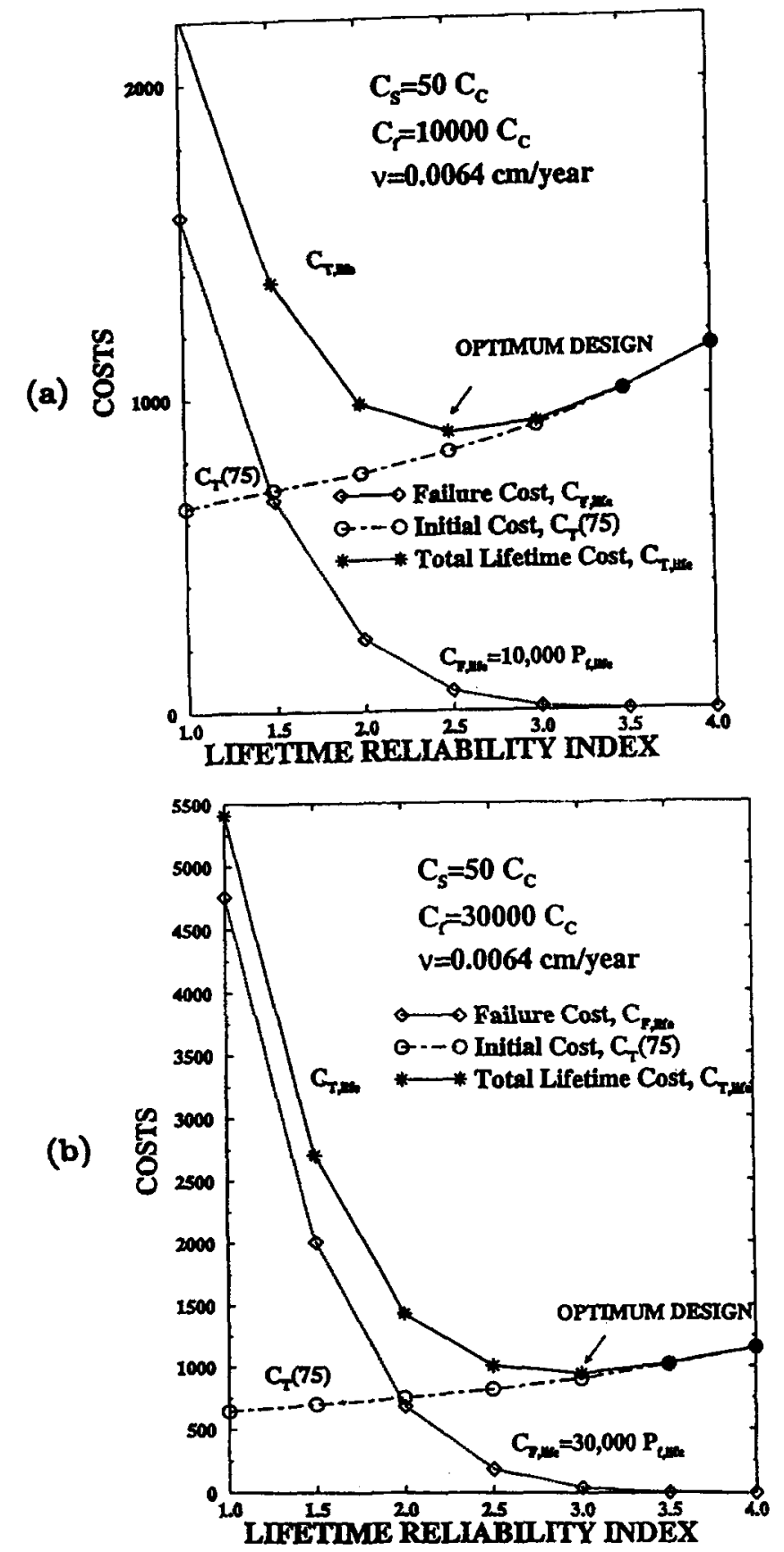

FIG. 13. Initial, Fallure, and Total Llfetime Costs versus Lifetime Reliability Index of RC T-Girders; Expected Cost Associated with Failure, $C_{F, \text { mo }}$ ls Three times Larger in (b) than in (a)

the total material cost and the total expected lifetime cost of the optimum solution. Also, it was shown that as the failure consequences are higher (i.e., failure cost increases) there is a need to design for an increased lifetime target reliability level.

Additional data on corrosion initiation and corrosion propagation rates in steel embedded in concrete, and failure costs of RC structures are necessary to reduce the degree of uncertainty associated with the proposed design approach. Also, data on cost and reliability of protection, inspection, and repair methods of RC structures exposed to aggressive environments are required for further development of a lifetime management strategy.
Further studies of the lifetime optimization process of RC girders under corrosion attack are needed. Topics for continued investigation include the consideration of: (1) modeling uncertainty in the diffusion and corrosion processes and in the evaluation of moment and shear capacities; (2) concrete cover as a design variable (increasing concrete cover may be a cheap and effective way to increase reliability in the presence of corrosion); (3) different and possibly nonuniform corrosion rates for the interior and exterior rebars; (4) cracking in the girders associated with mechanical processes such as freezethaw, tension cracks, etc., which allow quicker penetration of deicing salts to the level of rebars; (5) time-dependent effects on concrete shear strength and on yield strength of steel due to fatigue from the low level cyclic loading; and (6) repeated wetting and drying of the concrete at the surface in the diffusion process. Finally, reliability-based recommendations have to be developed to supplement existing American Concrete Institute and AASHTO provisions for handling corrosion to reinforcement of bridge structures.

\section{ACKNOWLEDGMENTS}

The support from the Chung-Shen Institute of Science and Technology, Taiwan, ROC, is gratefully acknowledged. The Institute made it possible for the second writer to pursue PhD work at the Department of Civil, Environmental, and Architectural Engineering, at the University of Colorado at Boulder. The partial financial support of the National Science Foundation through grants MSM-9013017, CMS-9319204, CMS9506435, and CMS-9522166 is also gratefully acknowledged.

\section{APPENDIX. REFERENCES}

Cady, P. D., and Weyers, R. E. (1984). "Deterioration rates of concrete bridge decks." J. Trans. Engrg., ASCE, 110(1), 34-44.

Frangopol, D. M., and Hendawi, S. (1994). "Incorporation of corrosion effects in reliability-based optimization of composite hybrid plate girders." Struct. Safety, 16(1/2), 145-169.

Frangopol, D. M., and Moses, F. (1994). "Reliability-based structural optimization." Advances in design optimization, H. Adeli, ed., Chapman \& Hall, Ltd., London, England, 492-570.

Hyman, W. A., and Hughes, D. J. (1983). "Computer model for lifecycle cost analysis of statewide bridge repair and replacement needs." Transp. Res. Rec., 899, Nat. Acad. of Sci., Washington, D.C., 52-61.

Kilareski, W. P. (1980). "Corrosion induced deterioration of reinforced concrete-an overview." Mat. Perf., Nat. Assn. Corrosion Engrs., Houston, Tex., 19(3), 48-50

Lin, K.-Y. (1995). "Reliability-based minimum life cycle cost design of reinforced concrete girder bridges," PhD thesis, Dept. of Civ., Envir., and Arch. Engrg., Univ. of Colorado, Boulder, Colo.

Lin, K.-Y., and Frangopol, D. M. (1996). "Reliability-based optimum design of reinforced concrete girders." Struct. Safety, 18(2/3), 239-258.

Mori, Y., and Ellingwood, B. R. (1994a). "Maintaining reliability of concrete structures I: role of inspection/repair." J. Struct. Engrg., ASCE, $120(3), 824-845$

Mori, Y., and Ellingwood, B. R. (1994b). "Maintaining reliability of concrete structures II: optimum inspection/repair." J. Struct. Engrg., ASCE, 120(3), 846-862.

Standard specifications for highway bridges, 15th Ed. (1992). Am. Assoc. of State Hwy. and Transp. Officials (AASHTO), Washington, D.C.

Takewaka, K., and Matsumoto, S. (1988). "Quality and cover thickness of concrete based on the estimation of chloride penetration in marine environments." Concrete in Marine Environment, V. M. Malhotra, ed. SP-109, Am. Concrete Inst. (ACI), Detroit, Mich., 381-400.

Thoft-Christensen, P. (1995). "Advanced bridge management systems." Struct. Engrg. Rev., 7(3), 149-266.

Ting, S.-C. (1989). "The effects of corrosion on the reliability of concrete bridge girders," PhD thesis, Dept. of Civ. Engrg., Univ. of Michigan, Ann Arbor, Mich.

Vanderplaats, G. N. (1986). ADS-a FORTRAN program for automated design synthesis. Version 1.10. Engineering Design Optimization Inc., Santa Barbara, Calif.

West, R. E., and Hime, W. G. (1985). "Chloride profiles in salty concrete." Mat. Perf., Nat. Assn. Corrosion Engrs., Houston, Tex., 24(7), 29-36. 